University of Nebraska - Lincoln

DigitalCommons@University of Nebraska - Lincoln

To Improve the Academy

Professional and Organizational Development Network in Higher Education

1996

Computer-Mediated Communication in the Classroom: Models for Enhancing Student Learning

\author{
Karin L. Sandell \\ Robert K. Stewart \\ Ohio University, stewartr@ohio.edu \\ Candace K. Stewart
}

Follow this and additional works at: https://digitalcommons.unl.edu/podimproveacad

Part of the Higher Education Administration Commons

Sandell, Karin L.; Stewart, Robert K.; and Stewart, Candace K., "Computer-Mediated Communication in the Classroom: Models for Enhancing Student Learning" (1996). To Improve the Academy. 363.

https://digitalcommons.unl.edu/podimproveacad/363

This Article is brought to you for free and open access by the Professional and Organizational Development Network in Higher Education at DigitalCommons@University of Nebraska - Lincoln. It has been accepted for inclusion in To Improve the Academy by an authorized administrator of DigitalCommons@University of Nebraska - Lincoln. 
Sandell, K. L., Stewart, R. K., and Stewart, C. K. (1996). Computer-mediated Communication in the Classroom: Models for Enhancing Student Learning. In L. Richlin (Ed.), To Improve the Academy, Vol. 15 (pp. 59-74). Stillwater, OK: New Forums Press and the Professional and Organizational Development Network in Higher Education. Key words: Computer-Mediated-Communication, Internet, Technology.

\section{Computer-Mediated Communication in the Classroom: Models for Enhancing Student Learning}

\section{Karin L. Sandell}

\section{Robert K. Stewart}

\section{Candace K. Stewart}

Ohio University

The introduction of computer-mediated communication into the college classroom has been a subject of concern to faculty interested both in exploring means of enhancing communication with their students and in facilitating students' learning about the technological revolution occurring in the business and professional worlds. The tools available to faculty include electronic mail (e-mail), bulletin boards, electronic conferencing, and electronic searching (or surfing) for information, via the Internet. This paper reviews the findings from different measures taken during a campus-wide project to test computer-mediated communication, in order to provide some suggestions about ways of enhancing the teaching-learning connection through classroom projects utilizing e-mail and the Internet. 
During the spring quarter of 1995, the Center for Teaching Excellence at Ohio University sponsored a campus-wide project to test computer-mediated communication applications for the classroom. The purpose of the project was to explore different models for using e-mail in the classroom; study ways of enhancing student familiarity with and use of e-mail, and examine the impact of e-mail use on subsequent student learning. The suggestions offered here also incorporate feedback received at the 1995 Professional \& Organizational Development (POD) Network in Higher Education Conference, where individuals attending a session where these data were presented also shared their experiences utilizing e-mail and the Internet.

The article is divided into three sections: a brief review of similar studies and articles; a description of the project and the results of data collected from the students and faculty who participated, and a list of suggestions for successfully utilizing these new technologies in order to enhance teaching and learning.

\section{Review of Relevant Literature}

The potential contributions of computer-mediated communication in the classroom mirror contributions realized in the business world. As Smith, Kim and Bernstein (1993) note, computer-mediated communication typically results in increased communication, particularly between individuals at different levels within a hierarchically structured organization. As the relationship between faculty and students represents this kind of structure, students should benefit from adoption of e-mail in the classroom. Increases in communication may be most pronounced when e-mail is used in large lecture classes, where the student-faculty hierarchical relationship is most likely to affect interaction. Further pedagogical benefits occur because of the increased student responsibility and autonomy facilitated by computermediated communication in the classroom (McComb, 1994).

In addition to increased opportunities for communication, e-mail and computer conferencing offer students more chances to interact with each other as they complete assignments, and as Holden and Wedman (1994) report, these are the kinds of assignments that are likely to predominate in the future. Interaction via computer networks 
allows students a more real-world experience that contributes to an enhanced educational setting for students, thus contributing to faculty interest in incorporating computer-mediated communication into their classrooms (Hunter, 1990). For example, studying a topic on one's own results in a certain amount of learning, but interacting with other students across campus, or even across the country, about that same topic leads to increased enthusiasm and to greater depth in the work output.

Other authors, such as Kemper (1991) note that distance education can be enhanced through computer-mediated communication. Students who are less likely to interact with other students in a collegial setting can benefit from the interaction possible via e-mail. Projects can be initiated and coordinated across the various branches of a campus or across several different campuses. On the other hand, students on remote or rural campuses may benefit from interaction with noted scholars through computer-mediated communication. Connections with individuals in other parts of the world are also possible, thus lending an intercultural dimension to a class that might otherwise not be there (Bailey and Cotlar, 1994).

The nature of the communication process itself and its relation to learning may come under scrutiny when students work with computermediated communication, according to Shedletsky (1993). The ways in which individuals process information rarely is discussed in the classroom. As students accommodate their intellectual processes to this new medium of communication, they are more likely to reflect on how they gather and make sense of new information. This increased focus on process, in turn, contributes to the enhancement of models for critical inquiry.

While these authors describe many of the possible applications of computer-mediated communication in the field, they also note some of the issues that arise in making this a positive learning experience for students. Most importantly, the use of e-mail, conferencing, bulletin boards, Internet access and so on must be structured into a class in a purposeful, pedagogically-sound manner (Everett and Ahern, 1994). Simply deciding to incorporate the technology without the appropriate educational context results in a confusing and potentially negative experience for students, who may perceive an exercise 
as ungrounded and therefore onerous. Yet, as Hawisher and Moran (1993) remind us, e-mail and other forms of computer-mediated communication are increasingly important in the world around us, and thus it is critical that we investigate the best means of incorporating e-mail into the classroom.

\section{Computer-mediated Communication Project: Description and Results}

Consideration of the issues reviewed above led the authors to develop a quarter-long project designed to critically examine the issues raised in the literature regarding successful integration of computer-mediated communication into the classroom. To make the test relevant to the actual courses being already taught on campus, the authors invited faculty to submit proposals detailing proposed computer applications for their spring quarter classes. From the proposals submitted by faculty across campus, 13 classes were selected for inclusion in the project. These 13 classes enrolled more than 700 students in subjects ranging from math to music to management. Different class sizes were evident, as well, with the smallest seniorlevel seminars enrolling 20 students and the largest an introductory plant biology class enrolling 400 students.

The assignments utilized in the classes offered a wide variety, as well. A popular application was the development and operation of class listservs. In some cases, these served simply to provide another source of information to students, while in other cases, they were utilized as a means of supporting class discussions on complicated topics. A second application required that students use e-mail to download and print articles. Yet another application required students to utilize connections to the Internet, in order to gather information for assignments. More complex assignments required that students conduct all of their class activities, including group projects and paper editing, electronically.

A number of different kinds of data were collected to assess the success of the project pedagogically, in terms of the three questions that guided definition of the project. Data were gathered from students through two means: a pre- and post-test questionnaire administered to 
all student participants and a series of focus groups that included two hundred selected students. The focus groups were meant to provide opportunities for the students to elaborate on their experiences with e-mail in the classroom.

\section{The Student Experience}

During the first class session in each of the thirteen classes, students were asked to complete a short questionnaire exploring their familiarity with, attitudes toward, and uses of e-mail. At the end of the quarter, students were asked to repeat the questionnaire, and respond

\section{TABLE 1}

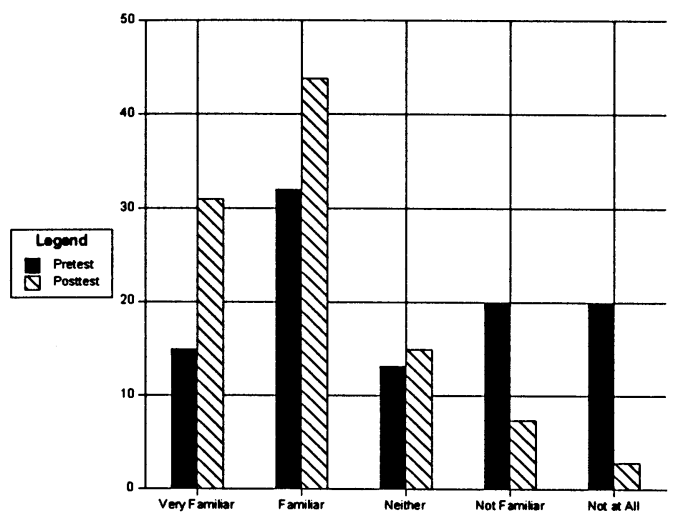

to some additional questions to provide a means of self-assessment of the amount of learning gained from the project.

As indicated in the Table 1 data, approximately 15 percent of these students were very familiar with e-mail before the project began. By the end of the project, this figure had more than doubled. In addition, while 20 percent of students were not at all familiar with e-mail at the start of the project, this figure dropped to fewer than 3 percent by the end.

Table 2 provides a comparison of e-mail use before and after the project. The primary use among those familiar with e-mail at the beginning of the quarter was communicating with other persons; by the end of the project, approximately the same number of students 


\section{TABLE 2}

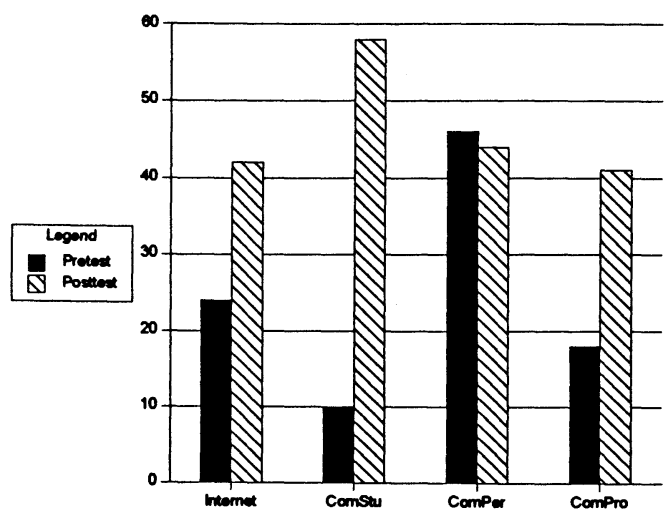

\section{TABLE 3}

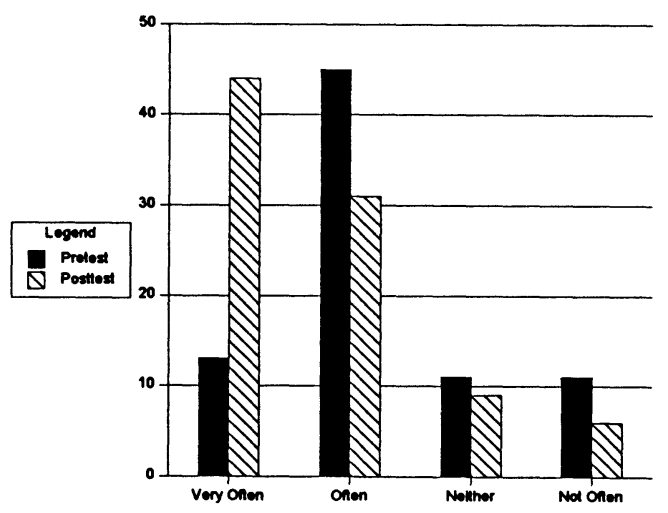

NOTE: Pretest totals in Table 3 do not add up to $100 \%$ because non-users were eliminated

were continuing to use e-mail to keep in touch with others. The smallest pre-test use, at 10 percent communicating with other students in class, had risen by the end of the project to the highest use, at 58 percent. Large gains also were recorded for communicating with 
professors, which more than doubled, from 18 percent to 41 percent, and accessing the Internet, which went from 24 percent to 42 percent. A gender difference emerged in these results, as well, with female students more likely to use e-mail to contact their professors or other students and male students more likely to access the Internet. This relationship held across different classes, thus making it less likely that this difference occurred as a function of a major, course focus, or discipline.

In Table 3, information regarding frequency of use is presented. Prior to the project, 13 percent of students used e-mail very often and 11 percent used it not often at all. By the end of the project, the first figure had changed considerably, with 44 percent of students indicating they used e-mail very often. Ironically, those not using e-mail often at all also increased, to 16 percent. While this latter increase is small, it nonetheless suggests that not all students were pleased with the decision to incorporate e-mail into their classroom. In fact, some students reported being very disturbed that they were expected to master a new skill in a class titled something other than "Computers in....".

A more useful measurement appears in Table 4, which presents a post-test measure of how much students felt their use of e-mail changed over the quarter. Only 5.5 percent of the students enrolled in

\section{TABLE 4}

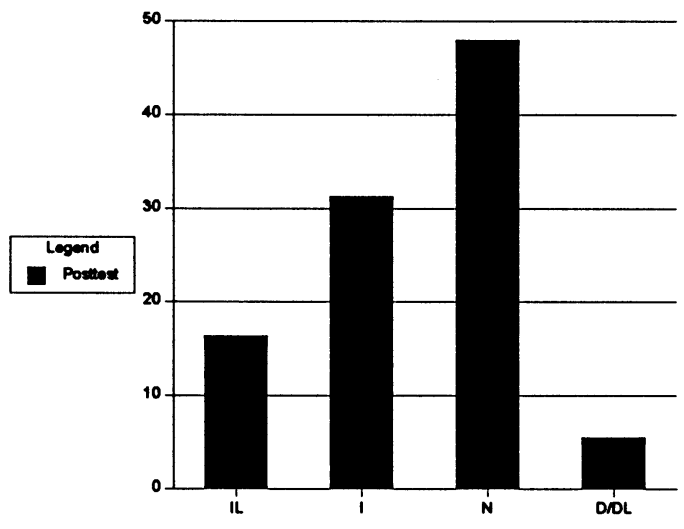


these classes found that their e-mail use either decreased or decreased a lot. In combination with the above findings, this suggests that some students decreased their e-mail usage while other students failed to ever begin using e-mail. More importantly, 46.6 percent of the students either increased or increased a lot their use of e-mail. Comparing this to the data in Table 2, it can be argued that the majority of this increase was in class assignments, as the same amount of communi-

\section{TABLE 5}

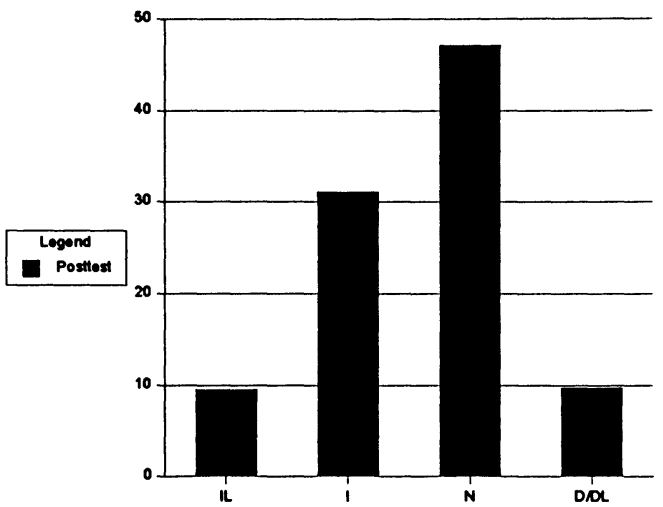

cating with friends took place both before and after the demonstration project.

Table 5 presents students' self-assessment of the amount their learning was enhanced from using e-mail in the classroom. Slightly more than 40 percent of students argued that their learning either increased or increased a lot, while 9.7 percent of students believed that use of e-mail had contributed to some decrease in their learning. One of the factors contributing to the apparent decrease in learning was the large number of student participants enrolled in an introductory plant biology course, in which students were required to download articles for their e-mail assignments. A number of them reported that they were unable to accomplish this. Thus, when they completed examinations and other course work, they were unable to perform well.

From the questionnaire data and from the focus groups, a number of suggestions were gleaned from students regarding ways of improving student success in working with e-mail. First and foremost, 
students argued that they needed more and better instruction. In particular, students who were given information on overheads fared the worst. Key points, such as the need to leave no spaces between a period and a letter in e-mail address and listserv subscriptions, failed to appear in the notes they took, with the result that some students experienced repeated frustration in subsequent futile attempts to accomplish their computer work. The students who were accompanied into a lab by their instructor fared the best. Somewhere between were those students who received information in writing and those students who received instruction in a lab, but outside of class (that is, in a session taught by someone other than the course instructor).

Students also argued that they needed more overall training in computer and printer use. Some students felt a level of comfort with e-mail but experienced total frustration when required to download and print from their e-mail. Students also felt the need for more support in helping them subscribe to the listservs set up for their classes. Although the procedure appeared simple to the various instructors, from a student point of view, it was much more confusing. In sum, students wanted more specific, hands-on, detailed information about e-mail, listservs, printers and other peripherals. This is an important point: most of the 13 instructors involved in this project initially overestimated their students' familiarity with and interest in using e-mail and computers, and thus underestimated the amount of support their students would need to complete their projects.

Although a small number of students argued that e-mail should not be used in future classes, the clear majority of students offered suggestions for ways in which e-mail could enhance their future class experiences. One problem that emerged early on concerned access to e-mail through both the university's computer labs and through the telephone lines from off-campus. Some students thus argued for more access and more facilities; until access could be improved, they suggested that e-mail assignments in classes should be optional or for extra credit rather than a required part of the class. In order to optimize use, they also noted that it could be best used in small classes and that limits should be set on the length of time students were allowed to work on computers in the labs. From an instructional point of view, students spending time communicating with others at remote cam- 
puses enhanced overall familiarity with and interest in e-mail; from a student point of view, other students communicating with their friends were seen as wasting time on computers that could have been devoted to assignments.

After students had experienced the ease of communicating with their professors electronically, they imagined accessing other information, especially grades. Students also wanted to learn more about using the Internet and wanted the university to develop conferencing capabilities through e-mail. This latter suggestion reflected the difficulties students typically have in setting up group projects; with such conferencing capabilities, they felt they could work together without having to all be in the same physical space.

Finally, from extensive conversations in the focus groups regarding the appropriateness of offering e-mail applications in the various classes, a key point emerged. The majority of students perceived computer-related skills as an instructional topic best taught in computer classes. As one student noted, "What do computers have to do with plant biology?" Going into this project, faculty assumed first that their students were ahead of them in adopting computer technology and thus would be eager to include computer-based assignments in their work. Second, they believed that students would perceive computer applications in a computers-across-the-curriculum kind of model. These data served to dispel a number of assumptions that faculty held. There appear to be a reasonably large number of computer-phobic students among the undergraduate population; they have not all grown up with video game and other technological skills that can be easily transferred to computer communications. Further, not all students perceive computer skills as an essential element in the educational process, nor do they understand fully the kinds of computer applications they will encounter in the workplace.

\section{The Faculty Experience}

The majority of the 13 faculty reported great success with their e-mail applications in the classroom. A number of conclusions emerged from their joint experiences, which will be explored later. Equally important are the problems that emerged in a few of the 
classes. Examination of these problems offers some further information regarding ways of enhancing e-mail applications in the classroom.

Some level of reluctance to get involved in the specific computer applications emerged in every class. This ranged from students expressing their frustration verbally, to students dragging their feet on the assignments, to students refusing to participate at all. In one large lecture class, some students were able to find friends or roommates with enough skill to download their assignments for them. In one of the senior seminars, which required that all the students' work be completed through e-mail, one student opted not to participate and suffered the grade consequences instead. No matter what the incentives or requirements placed around assignments by the faculty, a small number (usually somewhere between five and ten percent of students) did not get involved. One further point concerns the relationship between participation and whether assignments are required or not. As requirements increase, participation increases, as well. Despite the difficulties students had completing assignments due to limited access, their faculty concluded that it was important to require the computer assignments because this resulted in much higher participation and learning.

Students who attended classes that met daily were the least likely to use e-mail and listservs, while students who were enrolled in classes that met once or twice weekly were the most likely to use these technologies. For students who saw their instructors every day, or at least three days out of five, there was no incentive to make the effort to sign on to their e-mail accounts. If they had a question to ask, they could simply seek out the instructor before or after class. The only times students in these classes signed on was when there was some incentive or bonus for participation; even then, the number who took part typically was about half of the class. Students who attended classes that met less frequently were also less likely to see the instructor and thus utilized e-mail and listservs much more. The instructors in these classes were able to post reminders on their listservs and answer questions that occurred to students as they were reading over materials later in the week. 


\section{Recommendations on Using E-mail in the Classroom}

While accepting the basic assumption that the use of electronic communication can enhance the educational experience, this study also suggests the following ways to maximize the effectiveness of utilizing e-mail, listserv and Web resources:

1. Provide learning-friendly instructions; simplify and then simplify some more. Students are not necessarily familiar with the nuances of computer communication and thus may have difficulty grasping the exact nature of computer-mediated instructions. A corollary is to repeat instructions repeatedly.

2. Understand how students will experience computer-mediated communication. Faculty should be prepared to do anything that they ask their students to do. While personnel from computer support services or some similar group may be available for support and training, they should not be the sole source of information in the classroom. Instructors who can replicate student experiences will be better able to design classroom experiences that contribute to students' learning and liking.

3. Focus on the learning environment rather than the teaching environment or on technology in and of itself. The technology may allow for different applications, but it is important that these applications make sense within the structure of a particular course and with the pedagogical framework of that course. Students may need connections made for them, and assignments need to be made relevant to the course content to underscore the value of the computer application to the learning objectives.

4. Make assignments that utilize the computer component to provide much needed experience. The more familiar students are with computer-mediated communication, the more likely they are to reap the benefits of it as a learning tool.

5. Maximize interpersonal experiences by supplementing listservs or other more formal group communication with opportunities for individual interactions with students. Similarly, the experience of communicating via computer should be enhanced by responding to student mail as quickly as possible. Importantly, computer-me- 
diated communication should not be a substitute for interpersonal contact.

6. Bear in mind the implication for integrating computer-mediated communication into the course: while learning for some students is likely to be greatly enhanced, a small number of students will resist. These students should be considered when planning a course. For example, alternative assignments could be completed.

The following supplementary considerations were offered by participants at the 1995 POD conference.

7. Large classes, in particular, may benefit from peer-group instruction as a means of providing hands-on training. Research is beginning to demonstrate that students learn best in a computermediated environment when they are working in pairs. In this way, they can support each other as they work through difficult new situations.

8. Introduce computer-mediated communication gradually, moving from simple applications like e-mail to more complicated applications such as listservs and use groups, and finally to home pages and Web resources. Thus, enjoyment derived from increased use of technology through games and communication with friends and parents by e-mail is a useful starting point for many students and should be encouraged.

9. The on-line culture itself is worthy of consideration, particularly the quirky, sometimes complicated combination of informal interactions within a written medium. This may range from discussions of netiquette to consideration of the kinds of information processing issues that are involved in communicating through this medium.

\section{Conclusions}

While this research project did not utilize a control group and other factors may have contributed to the changes observed in the post test, the interviews with students in focus groups underscore the conclusions reached through analysis of the questionnaire data, suggesting 
that the class experiences with computer-mediated communication did contribute to these students' familiarity with and use of the technology.

Critical analysis of the 13 classroom experiences offered to students through this study of computer-mediated communication resulted in a number of important generalizations about student learning and use of technology. As familiarity with computer-mediated communication increased, the attitude toward it increased as well. Not surprisingly, as the attitude toward computer-mediated communication increased, the attitude toward the course where it was utilized increased as well. The opposite was also true, with a negative attitude toward e-mail, listserv, etc., corresponding to a negative attitude toward the class that incorporated the technology. Completing the set of relationships, it was found that a more positive attitude toward computer-mediated communication also led to greater use of it both inside and outside of class. The end result of the positive attitude and increased use was that more learning took place. As students got more involved in the various computer-mediated communication assignments in the 13 classes studied here, they gained both in attitude toward the technology and in overall learning from the class.

One last critical finding concerns the overall categories where use increased over the quarter. In every case, these uses were the assigned ones, rather than the individual uses students made of the technology. Thus, it would appear that the positive benefits which accrued to students from utilizing computer-mediated communication would not have occurred if the e-mail, listserv, network, Web resource and Internet assignments had not been made in the students' classes. This leads to the conclusion that the benefits of incorporating some sort of computer-mediated communication, within the limitations described above, are well worth it. The more students communicate electronically and the more they gain from their courses, the more they are becoming prepared to enter a world where computer-mediated communication is increasingly the norm.

Finally, students may resist these communication technologies and see them as less relevant to their majors and career foci than other skills such as writing. However, incorporating into classes interactivity that forces students to get on-line helps them begin using these technologies. Although the available technology may not have caught 
up to our teaching needs, it nonetheless has become vitally important in the business world. While access issues at a particular campus may suggest the need to offer computer-mediated communication as an option rather than a requirement, this study illustrates that the more opportunities students have to get on-line, the more they are going to become comfortable with computer-mediated communication.

\section{References}

Bailey, E.K., \& Cotlar, M. (1994). Teaching via the Internet. Communication Education, 43, 184-193.

Everett, D.R., \& Ahern, T.C. (1994). Computer-mediated communication as a teaching tool: A case study. Journal of Research on Computing in Education 26, 336-357.

Hawisher, G.E., \& Moran, C. (1993). Electronic mail and the writing instructor. College English, 55, 627-643.

Holden, M.C., \& Wedman, J.F. (1994). Future issues of computer-mediated communication: The results of a Delphi study. Educational Training, Research and Development, 41(4), 5-24.

Hunter, B. (1990, October). Computer-mediated communications support for teacher collaborations: Researching new contexts for both teaching and learning. Educational Technology, 46-49.

Kamper, R.J. (1991, November). Computer-mediated communication: conquest of time and space or just another technological seduction? Educational Technology, 20-25.

McComb, M. (1994). Benefits of computer-mediated communication in college courses. Communication Education, 43, 159- 170.

Shedletsky, L. (1993, December). Minding computer-mediated communication: CMC as experiential learning. Educational Technology, 5-10.

Smith, C., Kim, H., \& Bernstein, J. (1993, Spring). Computer-mediated communication and strategies for teaching: Instructional use of e-mail and bulletin boards. Journalism Educator, 80-83.

Contact:

Karin Sandell

Center for Teaching Excellence

101 Alden

Ohio University

Athens, OH 45701 USA

(614) 593-2681

(614) 593-0338 FAX

sandell@ouvaxa.cats.ohiou.edu

Karin Sandell received her doctorate in Media Studies from the University of Iowa. She taught in the School of Radio, Television and Film at Bowling Green State 
University for five years before joining the School of Telecommunications at Ohio University, where she has taught courses in women and media, politics and media, and research methods. Two years ago, she became the founding director of the Center for Teaching Ex cellence at Ohio University. Her published research focuses on the impact of mediated political messages on voters' decisio-making campaigns, particularly in relation to the formation of a gender gap in voting. She has recently begun exploring the role of technology in enhancing the learning environment in the college classroom.

Robert Stewart is an Associate Professor in the E.W. Scripps School of Journalism, Ohio University. He has Ph.D. and MA degrees in communications for the University of Washington. Research and teaching interests include broadcast journalism, international media, journalism history, and journalism on the World Wide Web.

Candace Stewart has an MA in English from Ohio University and teaches both first year and junior level composition courses. Her research interests include TA development in composition courses and the Internet as a teaching tool. In the fall of 1996, she will begin a $\mathrm{PhD}$ program in Rhetoric and Composition at Ohio University. In addition to her teaching duties, she will be the graduate assistant to Ohio University's Writing-Across-the-Curriculum Coordinator, a position that will include an emphasis on faculty development. 